\title{
Application of Data Engineering in Automatic information analysis for Electronic Customer Relationship Management: A Survey
}

\author{
Claudia C. Tusell-Rey ${ }^{1}$, Oscar Camacho-Nieto ${ }^{2}$, Ricardo Tejeida-Padilla ${ }^{3}$ \\ ${ }^{1}$ Escuela Superior de Turismo, Instituto Politécnico Nacional, Mexico, clautusellrey2014@gmail.com \\ ${ }^{2}$ Centro de Innovación y Desarrollo Tecnológico en Cómputo, Instituto Politécnico Nacional, Mexico, \\ ocnieto8@gmail.com \\ ${ }^{3}$ Escuela Superior de Turismo, Instituto Politécnico Nacional, Mexico, ricardotp75@hotmail.com
}

\begin{abstract}
In this paper we address Customer Relationship Management and electronic Customer Relationship Management from the perspective of the confluence of two relevant areas of engineering: Behavioral Engineering and Data Engineering. After conducting extensive documentary research on the state of the art,we review some of the most recent works of automatic data analysis applied to the tourism industry, considering the particularities of Behavioral Engineering within the systemic paradigm. As a result of this research work, one of the most important conclusions we have reached is the following: we determine that, to obtain an efficient electronic Customer Relationship Management model in a tourism related organization, the use of Intelligent Computing techniques for automatic data analysis is needed to ostensibly improve working conditions related to the tourism industry.
\end{abstract}

Key words :data engineering, information systems, customer relationship management, behavioral engineering, tourism.

\section{INTRODUCTION}

The information obtained from customers can be varied, dispersed, and with high volumes of data. In this research, we refer to the analysis of information in three aspects within the Customer Relationship Management (CRM): customer satisfaction, the study of customer behavior and the forecast of tourism demand. When CRM is carried out by electronic means, it is referred as electronic CRM, or just eCRM.

The process through which users create and share opinions about brands, products and services, that is, electronic word of mouth (electronic Word-Of-Mouth, eWOM) is gaining more and more attention [1].

Tourism organizations need to constantly monitor their guests' online activities, and respond quickly to expressed problems, concerns, or dissatisfactions.
This is because good reviews, which convey a positive attitude, can attract new tourists, while bad reviews, which convey negative emotions, can damage the reputation of the organization, given that customers trust review websites more than professional guides and travel agencies, and perceive social media as more credible and reliable than traditional marketing communications Grljević, Bošnjak, \& Bošnjak, 2019). Thus, recommendation systems can make suggestions to users according to their preferences [2].

Due to the large amount of content that is posted daily in the form of reviews, manual analysis of reviews becomes difficult and time consuming.

That is why various computational strategies have been used to divide the reviews into three types: positive, neutral or negative, through the analysis of feelings [3-5].

This theme is currently very active, having been applied in countries such as China[6], the Sultanate of Oman [3], Serbia [7], Spain [8,9] among others. Text mining has also been used to establish tourist preferences in Japan[10].

This paper is organized as follows: section II analyzes some of the current research about eCRM in tourism, section III offers some works on automatic data analysis and applications for tourism, and section IV offers the conclusions.

\section{ECRM IN TOURISM: CURRENT TRENDS}

Among the important industries of a country is tourism, because human beings are prone to experiences in places that are outside their habitat[11].

In addition to human entertainment as a widespread characteristic of tourism, the types of this industry range from adventure and relaxation to cultural and catastrophic. There is also religious tourism and many more types[12, 13]. Regardless of the possible variants of tourism, the importance of this activity is undeniable [14]. 
Claudia C. Tusell-Rey et al., International Journal of Emerging Trends in Engineering Research, 8(9), September 2020, 5939 - 5946

Currently, tourists are more demanding, are better informed, and require greater attention [15]. That is why in tourism organizations the customer relationship management paradigm (Customer Relationship Management, CRM) is fundamental $[16,17]$.

Tourism organizations are among the first to adopt this type of strategy. Let us illustrate this fact with what happened to the Ritz Carlton firm. This company adopted computer and information systems to provide personalized service to the opinions and services addressed to customers. These innovations earned him the 1987 Malcom Baldridge award[18].

It is considered essential for success to achieve the rapid identification of customer needs, and also to reach potential customers with up-to-date, personalized and comprehensive information. All this to achieve profitable clients [15]. Customer profitability has been deeply studied in the administrative field.

One of the factors that positively influence customer profitability is their loyalty [19]. Loyalty is defined as repetitive purchasing behavior [20], and loyal customers have been shown to be less sensitive to price changes [19].

\subsection{Definitions of CRM and eCRM}

The systemic paradigm has been widely adopted and used today, as well as by social psychologists in the study of organizations using Behavioral Engineering techniques [16].

There are numerous examples of its use in operations, as well as in the trend towards automation in which a self-dividing system with inputs, outputs and a control mechanism is envisaged. It has been used as the organizational base of different space and military programs in which it was impossible to treat the parts of the system as separate entities. It is also used in many other types of projects that require the integration of a multitude of agents and activities, such as transport projects, pollution control and urban traffic, among others [8].

With the development of new conceptual schemes, which present a different point of view, great changes have taken place in all fields of science. Systems Theory, or systemic paradigm, allows studying the management of organizations, as systems that interact with other agents that make up their immediate neighborhood. This also facilitates the understanding of the interrelationships between the main components of an organization: its objectives, technology, structure, and psychosocial relationships [21, 22].

One of the strong reasons for the existence of organizations is their synergistic effect, that is, the sum of the inputs may differ in quantity or quality in the result of an organization. In the same way, every participant in the organization expects that the personal benefits of their participation in an organization will be greater than their personal costs of participation. In this sense, the synergistic factor of organizations are undeniable sources of dividends: organizational synergy produces wealth [7].

CRM is defined as all marketing activities directed towards the establishment, development, and maintenance of satisfactory relational exchanges with customers [21]. Also, Grönroos defines it as "identifying and establishing, maintaining and improving and, when necessary, also ending relationships with clients and other interested parties, for profit, so that the objectives of all parties are met, and let this be done through mutual exchange and the fulfillment of promises” [22].

On the other hand, CRM has also been defined as "a business strategy that includes a combination of people, processes and technologies through all points of contact with customers, including marketing, sales, and customer service” [23]. More recently, CRM is defined as "the approach that involves the process of identifying, attracting, developing and maintaining successful relationships with clients to increase retention of profitable clients" [16].

With the emergence of new information and communication technologies, CRM has evolved in the digital age, giving way to eCRM (electronic CRM), where marketing activities have at least one virtual component.

eCRM refers to marketing activities, tools and techniques, delivered with the use of the Internet for the specific purpose of locating, building and improving long-term relationships with customers, to enhance their individual potential [19]. An eCRM allows you to capture or build a record of each individual, and carry out all those operations typical of record management in organizations. For example, it is possible to carry out detailed analyzes to be able to personalize that record according to the history or the past, present and future needs, through technical predictions. Communication is also important and eCRM facilitates this aspect of interactions[23].

eCRM includes enterprise-level global data storage and analysis, customization, and integration of multi-channel communication subsystems. This allows companies to track and manage the profitability of customers, their behavior, and achieve their satisfaction at a reasonable cost [17]. However, although eCRM is closely linked to information and communication technologies, it cannot be seen solely as a computational application. Rather, eCRM should be viewed as a combination of hardware, software, human resources, processes, applications, and management commitments, seeking to attract and keep valuable customers, and improving marketing effectiveness through creating and delivering maximum value for customers [17]. 
Claudia C. Tusell-Rey et al., International Journal of Emerging Trends in Engineering Research, 8(9), September 2020, 5939 - 5946

\section{AUTOMATIC DATA ANALYSIS AND ITS APPLICATION TO TOURISM ECRM}

Intelligent Computing is a discipline that formally belongs to the area of Data Engineering, and emerged in the 90s of the last century[24, 25]. Its fundamental objective is to perform engineering tasks to extract knowledge from existing data. Intelligent Computing comprises data preprocessing [26-35], data transformation [36-48], and decision making [49-75].

This discipline is used in numerous fields, such as education [35, 57-62, 76], finances [65, 69], medicine [58, 64, 68, 70, 72], engineering [41-44, 46-48, 77], environment [50, 66, 75], and others $[67,71,73,78]$. In the tourism field, this discipline has been applied in numerous ways. In this research, we refer to three of them: the analysis of customer satisfaction, the study of customer behavior and the forecast of tourist demand.

The arrival of the internet, and specifically the World Wide Web, has meant a true revolution in all human activities. Obviously, tourism is no exception and (Internet + Travel) has emerged, which provides a large number of advantages in tourist activities. To mention just a few examples, this virtuous hybridization gives travelers instant travel and tour data, effortlessly. In addition, collaborative environments open an ocean of possibilities for both companies and tourists from around the world. There are users who upload reviews to social networks of their stays in different places. This valuable information is gold for many travelers. These reviews allow travelers to know in advance the characteristics of the tourist sites and thus avoid problems during their trip or their stay in a certain place [79].

$\mathrm{Yu}$ and collaborators automatically extracted reviews of Chinese tourist attractions from a Japanese travel website called 4Travel[79]. The findings of these researchers can provide practical guidelines for use within the field of sentiment analysis from Japanese online tourism reviews and facilitate the improvement of tourist attraction service.

Web searches are of increasing importance in travel planning, and in the practice of tourism in general, as users search for information regarding places of interest, lodging, weather and others. In Law and collaborators' research, these searches are used to forecast tourism demand in Macao. To do this, they used deep learning[80].

The data set used in this research was made available to the interested public under the name "Macau2018" on the site http://github.com/tulip-lab/open-data.

Also, Sun and collaborators investigated the forecast of tourist demand, this time in Beijing[81]. In this case, the kernel extreme learning machine (KELM) was used. In this case, no data is available.

Zhang and collaborators have also investigated the forecast of the demand for sports tourism[82], while other researchers have done so in the classification of tourist scenarios [83, 84].
On the other hand, information from social networks has also been used to identify tourist attractions[85] and user behavior[86].

In the first case, information was taken from geotagged photographs and uploaded to social networks to determine tourist attractions in six cities in ItalyItalia [85]. These images were taken from the Flickr platform (www.flickr.com).

If someone wants to add value to their photos, such as latitude and longitude location coordinates, Flickr is the answer. In addition to the location, you can provide the date and time, because Flickr works with photos online

Flickr images are a two-edged sword, because the information in the photos is abundant. This excess of information can encourage antisocial and even criminal behavior. Therefore, users must be very careful when publishing their photos. On the other hand, these photos uploaded to Flickr can be of great use to travelers with common interests and to follow the successful and pleasant journeys of other users [85].

In the second case, information was taken from the YFCC 100M photo database, which contains 48366323 geotagged images. Of these, the Beijing City Laboratory selected the 2171162 photos for China. Of these, a total of 35,356 photos correspond to the city of Beijing and were taken by foreign tourists; These are part of the study by Zhang et al. [86].

Tourist sites can greatly benefit from current technical knowledge. By innovating and adapting state-of-the-art technology, tourism promotion and marketing can be empowered in surprising ways. If a tourism entrepreneur knows the behavior and interests of travelers, the possibilities for the business to flourish are (almost) endless. It is enough to take advantage of the new information and communication technologies in a smart way[86].

In particular, Zhang et al.'s research showed that tourists from four continents analyzed had significant differences in the perception of buildings, natural phenomena, mountains, culture, plants, insects and animals, and traffic[86].

Furthermore, influenced by cultural, social and economic factors, tourist preferences and recreational needs are complicated and diverse, but there are groups among users. This is why these specific results could provide clues for a more appropriate and detailed marketing promotion for destination management organizations (DMOs)[86].

For a different purpose, Swamp and Dennis also used information from Flickr photos. In this case, the authors decided to work with a specific case. They studied Harrods (London, United Kingdom) to investigate the influence that a luxury store has on the degree of attraction that that specific site generates in potential users[87].

The results showed that the Harrods building is central in most of the images analyzed, representing the main point photographed within a radius of $1 \mathrm{~km}$, and the exterior of the 
Claudia C. Tusell-Rey et al., International Journal of Emerging Trends in Engineering Research, 8(9), September 2020, 5939 - 5946

building is added as an attribute of the department stores and demonstrates the role of large warehouses in the appeal of a place.The study also offers helpful suggestions for marketing managers to develop more personalized retail strategies[87].

An organization is a group of people grouped together in order to obtain a goal or objective, through a method or plan of action and who have the resources to do so [88].

The concept of the word "system" is crucial to establish the theoretical analytical bases that allow organizations to be abstracted from their systemic character. In this context, the word acquires specific connotations of the field of study. It is a matter of considering a certain specific purpose, the scope of which depends very significantly on certain relationships that form well-established patterns. These patterns allow researchers to theoretically analyze organizations from the systemic paradigm. The concept of organization, then, becomes a well-defined network of systems that brings together resources of all types related to each other: they can be structural, infrastructure, social, human, labor or emotional.

There is a great variety of systems in the universe. There are medical systems [89], expert systems [90], academic systems [91], transport systems [92], control systems [93], fuzzy systems [94], quantum systems [95], transfer systems [96], and tracking systems [97], among many others.

The systems act as arteries that transport resources to generate productive and distributive processes, to become the means of satisfying the needs of groups of members. There are internal systems whose function is to connect with each other to other systems of the organization [7].

They supply goods and services consumed in the organization itself during efforts to fulfill its missions. An example could be the communication system, which provides the information necessary to maintain the organization and its operations.

The systems approach applied to the management concept analyzes the organization as a united and directed system composed of interrelated parts.

\section{CONCLUSION}

Derivate from the previous analysis, we can assess the importance of computational intelligence models in tourism development. They have a key role in eCRM, as well as in taking advance of human behavior for further growth of tourism destinations. As future work, we want to analyze the impact of Internet of Things technologies in the 21rst century tourism.

\section{ACKNOWLEDGEMENT}

The authors want to thank the InstitutoPolitécnico Nacional, Mexico (SecretaríaAcadémica, EST, CIDETEC, COFAA), the CONACYT and SNI for their support in the development of this work.

\section{REFERENCES}

1. I. Erkan and C. Evans. The influence of eWOM in social media on consumers' purchase intentions: An extended approach to information adoption, Computers in Human Behavior, vol. 61, pp. 47-55, 2016.

2. C. Chatzigeorgiou, P. Kasnesis, and L. G. Toumanidis. Exploiting Edge Computing for Privacy Aware Tourism Demand Forecasting, IT Professional, vol. 21, pp. 19-25, 2019.

3. V. Ramanathan and T. Meyyappan. Twitter Text Mining for Sentiment Analysis on People's Feedback about Oman Tourism, in 2019 4th MEC International Conference on Big Data and Smart City (ICBDSC), 2019, pp. 1-5.

4. M. Afzaal, M. Usman, and A. Fong. Tourism Mobile App With Aspect-Based Sentiment Classification Framework for Tourist Reviews, IEEE Transactions on Consumer Electronics, vol. 65, pp. 233-242, 2019.

5. A. R. Alaei, S. Becken, and B. Stantic. Sentiment analysis in tourism: capitalizing on big data, Journal of Travel Research, vol. 58, pp. 175-191, 2019.

6. Y. Fu, J.-X. Hao, X. Li, and C. H. Hsu. Predictive Accuracy of Sentiment Analytics for Tourism: A Metalearning Perspective on Chinese Travel News, Journal of Travel Research, vol. 58, pp. 666-679, 2019.

7. O. Grljević, Z. Bošnjak, and S. Bošnjak. Contemporary data analysis techniques for online reputation management in hospitality and tourism, Facta Universitatis, Series: Economics and Organization, vol. 16, pp. 59-73, 2019.

8. A. García, S. Gaines, and M. T. Linaza. A lexicon based sentiment analysis retrieval system for tourism domain, $e$-Review of Tourism Research, vol. 10, pp. 35-38, 2012.

9. M. R. González-Rodríguez, R. Martínez-Torres, and S. Toral. Post-visit and pre-visit tourist destination image through eWOM sentiment analysis and perceived helpfulness, International Journal of Contemporary Hospitality Management, vol. 28, pp. 2609-2627, 2016.

10. C. Zeng, T. Nakatoh, S. Hirokawa, and M. Eguchi. Text mining of tourism preference in a multilingual site, IEEJ Transactions on Electrical and Electronic Engineering, vol. 14, pp. 590-596, 2019.

11. C. L. Morley. What is tourism? Definitions, concepts and characteristics, Journal of Tourism Studies, vol. 1, pp. 3-8, 1990.

12. A. M. Benur and B. Bramwell. Tourism product development and product diversification in destinations, Tourism Management, vol. 50, pp. 213-224, 2015.

13. B. Boniface, R. Cooper, and C. Cooper. Worldwide destinations: The geography of travel and tourism: Routledge, 2016. 
14. M. Peters, J. Frehse, and D. Buhalis. The importance of lifestyle entrepreneurship: A conceptual study of the tourism industry, Pasos, vol. 7, pp. 393-405, 2009.

15. A. Papaioannou, C. Kariofyllas, K. Koronios, A. Kourtesopoulou, and A. Kriemadis. Exploring E-CRM application: The case of tourism and hospitality industry in greece, Journal of Regional Socio-Economic Issues (Jrsei), vol. 4, pp. 75-84, 2014.

16. M. Sigala. eCRM 2.0 applications and trends: The use and perceptions of Greek tourism firms of social networks and intelligence, Computers in Human Behavior, vol. 27, pp. 655-661, 2011.

17. G. Mastorakis, N. Trihas, E. Perakakis, and I. Kopanakis. E-CRM in tourism exploiting emerging information and communication technologies, Anatolia, vol. 26, pp. 32-44, 2015.

18. C. A. Vogt. Customer relationship management in tourism: Management needs and research applications, Journal of Travel Research, vol. 50, pp. 356-364, 2011.

19. L. Lee-Kelley, D. Gilbert, and R. Mannicom. How e-CRM can enhance customer loyalty, Marketing Intelligence \& Planning, vol. 21, pp. 239-248, 2003.

20. C. K. Yim and P. Kannan. Consumer behavioral loyalty, Journal of business research, vol. 44, pp. 75-92, 1999.

21. R. M. Morgan and S. D. Hunt. The commitment-trust theory of relationship marketing, Journal of marketing, vol. 58, pp. 20-38, 1994.

22. C. Grönroos. Relationship marketing: strategic and tactical implications, Management decision, vol. 34, pp. 5-14, 1996.

23. Y. Wang and D. R. Fesenmaier. Towards understanding members' general participation in and active contribution to an online travel community, Tourism management, vol. 25, pp. 709-722, 2004.

24. J. C. Bezdek. On the relationship between neural networks, pattern recognition and intelligence, International journal of approximate reasoning, vol. 6, pp. 85-107, 1992.

25. J. C. Bezdek. Computational intelligence defined-By everyone!, in Computational Intelligence: Soft Computing and Fuzzy-Neuro Integration with Applications, ed: Springer, 1998, pp. 10-37.

26. M. A. Medina-Pérez, M. García-Borroto, Y. Villuendas-Rey, and J. Ruiz-Shulcloper. Selecting objects for ALVOT, in Iberoamerican Congress on Pattern Recognition, 2006, pp. 606-613.

27. Y. Villuendas-Rey, M. García-Borroto, M. A. Medina-Pérez, and J. Ruiz-Shulcloper. Simultaneous features and objects selection for Mixed and Incomplete data, in Iberoamerican Congress on Pattern Recognition, 2006, pp. 597-605.

28. Y. Villuendas-Rey, M. García-Borroto, and J. Ruiz-Shulcloper. Selecting features and objects for mixed and incomplete data, in Iberoamerican Congress on Pattern Recognition, 2008, pp. 381-388.

29. M. García-Borroto, Y. Villuendas-Rey, J. A. Carrasco-Ochoa, and J. F. Martínez-Trinidad. Using maximum similarity graphs to edit nearest neighbor classifiers, in Iberoamerican Congress on Pattern Recognition, 2009, pp. 489-496.

30. M. García-Borroto, Y. Villuendas-Rey, J. A. Carrasco-Ochoa, and J. F. Martínez-Trinidad. Finding small consistent subset for the nearest neighbor classifier based on support graphs, in Iberoamerican Congress on Pattern Recognition, 2009, pp. 465-472.

31. Y. Villuendas-Rey, Y. Caballero-Mota, and M. M. García-Lorenzo. Using rough sets and maximum similarity graphs for nearest prototype classification, in Iberoamerican Congress on Pattern Recognition, 2012, pp. 300-307.

32. Y. Villuendas-Rey, Y. Caballero-Mota, and M. M. García-Lorenzo. Intelligent feature and instance selection to improve nearest neighbor classifiers, in Mexican International Conference on Artificial Intelligence, 2012, pp. 27-38.

33. Y. Villuendas-Rey, Y. Caballero-Mota, and M. M. García-Lorenzo. Prototype selection with compact sets and extended rough sets, in Ibero-American Conference on Artificial Intelligence, 2012, pp. 159-168.

34. Y. Villuendas-Rey, C. Rey-Benguría, Y. Caballero-Mota, and M. M. García-Lorenzo. Nearest prototype classification of special school families based on hierarchical compact sets clustering, in Ibero-American Conference on Artificial Intelligence, 2012, pp. 662-671.

35. Y. Villuendas-Rey, C. Rey-Benguría, M. Lytras, C. Yáñez-Márquez, and O. Camacho-Nieto. Simultaneous instance and feature selection for improving prediction in special education data, Program, vol. 51, pp. 278-297, 2017.

36. I. Roman-Godinez, I. Lopez-Yanez, and C. Yanez-Marquez. A new classifier based on associative memories, in 2006 15th International Conference on Computing, 2006, pp. 55-59.

37. M. E. Acevedo-Mosqueda, C. Yáñez-Márquez, and I. López-Yáñez. Alpha-Beta bidirectional associative memories: theory and applications, Neural Processing Letters, vol. 26, pp. 1-40, 2007.

38. E. Guzman, S. Alvarado, O. Pogrebnyak, and C. Yanez. Image recognition processor based on morphological associative memories, in Electronics, Robotics and Automotive Mechanics Conference (CERMA 2007), 2007, pp. 260-265.

39. C. Yáñez-Márquez, M. E. Cruz-Meza, F. A. Sánchez-Garfias, and I. López-Yáñez. Using alpha-beta associative memories to learn and recall RGB images, in International Symposium on Neural Networks, 2007, pp. 828-833.

40. E. Guzmán, O. Pogrebnyak, C. Yañez, and L. P. S. Fernandez. Morphological transform for image 
compression, EURASIP Journal on advances in signal processing, vol. 2008, p. 426580, 2008.

41. I. J. Rudas, I. Z. Batyrshin, A. H. Zavala, O. C. Nieto, L. Horváth, and L. V. Vargas. Generators of fuzzy operations for hardware implementation of fuzzy systems, in Mexican International Conference on Artificial Intelligence, 2008, pp. 710-719.

42. I. J. Rudas, I. Z. Batyrshin, A. H. Zavala, O. C. Nieto, and L. V. Vargas. Digital fuzzy parametric conjunctions for hardware implementation of fuzzy systems, in 2009 IEEE International Conference on Computational Cybernetics (ICCC), 2009, pp. 157-166.

43. A. H. Zavala, I. Z. Batyrshin, I. J. Rudas, L. V. Vargas, and O. C. Nieto. Parametric operations for digital hardware implementation of fuzzy systems, in Mexican International Conference on Artificial Intelligence, 2009, pp. 432-443.

44. A. H. Zavala, O. C. Nieto, I. Batyrshin, and L. V. Vargas. VLSI Implementation of a Module for Realization of Basic t-norms on Fuzzy Hardware, in 2009 IEEE International Conference on Fuzzy Systems, 2009, pp. 655-659.

45. S. J. Lopez, O. C. Nieto, and J. I. C. Oria. Non-parametric modeling of uncertain hyperbolic partial differential equations using pseudo-high order sliding mode observers, International Journal of Innovative Computing, Information and Control, vol. 8, pp. 1501-1521, 2012.

46. A. H. Zavala, I. Z. Batyrshin, O. C. Nieto, and O. Castillo. Conjunction and disjunction operations for digital fuzzy hardware, Applied Soft Computing, vol. 13, pp. 3248-3258, 2013.

47. I. Salgado, O. Camacho, C. Yáñez, and I. Chairez. Proportional derivative fuzzy control supplied with second order sliding mode differentiation, Engineering Applications of Artificial Intelligence, vol. 35, pp. 84-94, 2014.

48. I. Salgado, I. Chairez, O. Camacho, and C. Yañez. Super-twisting sliding mode differentiation for improving PD controllers performance of second order systems, ISA transactions, vol. 53, pp. 1096-1106, 2014.

49. P. Moreno-Moreno and C. Yáñez-Márquez. The new informatics technologies in education debate, in World Summit on Knowledge Society, 2008, pp. 291-296.

50. C. Yáñez-Márquez, I. López-Yáñez, and G. d. l. L. S. Morales. Analysis and prediction of air quality data with the gamma classifier, in Iberoamerican Congress on Pattern Recognition, 2008, pp. 651-658.

51. I. López-Yáñez, A. J. Argüelles-Cruz, O. Camacho-Nieto, and C. Yáñez-Márquez. Pollutants time-series prediction using the Gamma classifier, International Journal of Computational Intelligence Systems, vol. 4, pp. 680-711, 2011.

52. L. Cleofas-Sánchez, V. García, R. Martín-Félez, R. Valdovinos, J. S. Sánchez, and O. Camacho-Nieto.
Hybrid associative memories for imbalanced data classification: an experimental study, in Mexican Conference on Pattern Recognition, 2013, pp. 325-334.

53. Y. Villuendas-Rey, M. M. Garcia-Lorenzo, and R. Bello. Support Rough Sets for decision-making, in Fourth International Workshop on Knowledge Discovery, Knowledge Management and Decision Support, 2013.

54. I. López-Yáñez, L. Sheremetov, and C. Yáñez-Márquez. A novel associative model for time series data mining, Pattern Recognition Letters, vol. 41, pp. 23-33, 2014.

55. M. D. Lytras, H. Mathkour, H. I. Abdalla, C. Yáñez-Márquez, and P. O. De Pablos. The Social Media in Academia and EducationResearch R-evolutions and a Paradox: Advanced Next Generation Social Learning Innovation, J. UCS, vol. 20, pp. 1987-1994, 2014.

56. Y. Villuendas-Rey and M. M. Garcia-Lorenzo. Attribute and case selection for $\mathrm{nn}$ classifier through rough sets and naturally inspired algorithms, Computación y Sistemas, vol. 18, pp. 295-311, 2014.

57. C. Yáñez-Márquez, M. Aldape-Perez, I. López-Yáñez, and O. Camacho-Nieto. Emerging computational tools: Impact on engineering education and computer science learning, International Journal of Engineering Education, pp. 533-542, 2014.

58. M. Aldape-Pérez, C. Yáñez-Márquez, O. Camacho-Nieto, I. López-Yáñez, and A.-J. Argüelles-Cruz. Collaborative learning based on associative models: Application to pattern classification in medical datasets, Computers in Human Behavior, vol. 51, pp. 771-779, 2015.

59. I. López-Yáñez, C. Yáñez-Márquez, O. Camacho-Nieto, M. Aldape-Pérez, and A.-J. Argüelles-Cruz. Collaborative learning in postgraduate level courses, Computers in Human Behavior, vol. 51, pp. 938-944, 2015.

60. A. Ferreira-Santiago, C. Yanez-Marquez, I. Lopez-Yanez, O. Camacho-Nieto, M. Aldape-Perez, and A. J. Arguelles-Cruz. Enhancing engineering education through link prediction in social networks, International Journal of Engineering Education, pp. 1566-1578, 2016.

61. S. Cerón-Figueroa, I. López-Yáñez, W. Alhalabi, O. Camacho-Nieto, Y. Villuendas-Rey, M. Aldape-Pérez, et al.Instance-based ontology matching for e-learning material using an associative pattern classifier, Computers in Human Behavior, vol. 69, pp. 218-225, 2017.

62. A. García-Floriano, A. Ferreira-Santiago, C. Yáñez-Márquez, O. Camacho-Nieto, M. Aldape-Pérez, and Y. Villuendas-Rey. Social Web Content Enhancement in a Distance Learning Environment: Intelligent Metadata Generation for Resources, 
International Review of Research in Open and Distributed Learning, vol. 18, pp. 161-176, 2017.

63. S. Ortiz-Ángeles, Y. Villuendas-Rey, I. López-Yáñez, O. C. Nieto, and C. Yáñez-Márquez. Electoral Preferences Prediction of the YouGov Social Network Users Based on Computational Intelligence Algorithms, J. UCS, vol. 23, pp. 304-326, 2017.

64. R. Ramírez-Rubio, M. Aldape-Pérez, C. Yáñez-Márquez, I. López-Yáñez, and O. Camacho-Nieto. Pattern classification using smallest normalized difference associative memory, Pattern Recognition Letters, vol. 93, pp. 104-112, 2017.

65. Y. Villuendas-Rey, C. F. Rey-Benguría, Á. Ferreira-Santiago, O. Camacho-Nieto, and C. Yáñez-Márquez. The naïve associative classifier (NAC): a novel, simple, transparent, and accurate classification model evaluated on financial data, Neurocomputing, vol. 265, pp. 105-115, 2017.

66. J. A. Antón-Vargas, Y. Villuendas-Rey, C. Yáñez-Márquez, I. López-Yáñez, and O. Camacho-Nieto. Improving the performance of an associative classifier by Gamma rough sets based instance selection, International Journal of Pattern Recognition and Artificial Intelligence, vol. 32, p. 1860009, 2018.

67. E. Barroso, Y. Villuendas, and C. Yanez. Bio-inspired algorithms for improving mixed and incomplete data clustering, IEEE Latin America Transactions, vol. 16, pp. 2248-2253, 2018.

68. D. González-Patiño, Y. Villuendas-Rey, and A. J. Argüelles-Cruz. The potential use of bioinspired algorithms applied in the segmentation of mammograms, 2018.

69. Y. O. Serrano-Silva, Y. Villuendas-Rey, and C. Yáñez-Márquez. Automatic feature weighting for improving financial Decision Support Systems, Decision Support Systems, vol. 107, pp. 78-87, 2018.

70. Y. Villuendas-Rey, M. D. Alanis-Tamez, C. Rey-Benguría, C. Yáñez-Márquez, and O. C. Nieto. Medical Diagnosis of Chronic Diseases Based on a Novel Computational Intelligence Algorithm, $J$. UCS, vol. 24, pp. 775-796, 2018.

71. C. Yáñez-Márquez, I. López-Yáñez, M. Aldape-Pérez, O. Camacho-Nieto, A. J. Argüelles-Cruz, and Y. Villuendas-Rey. Theoretical Foundations for the Alpha-Beta Associative Memories: 10 Years of Derived Extensions, Models, and Applications, Neural Processing Letters, vol. 48, pp. 811-847, 2018.

72. D. González-Patiño, Y. Villuendas-Rey, A.-J. Argüelles-Cruz, and F. Karray. A Novel Bio-Inspired Method for Early Diagnosis of Breast Cancer through Mammographic Image Analysis, Applied Sciences, vol. 9, p. 4492, 2019.

73. Y. Villuendas-Rey. Maximal similarity granular rough sets for mixed and incomplete information systems, Soft Computing, vol. 23, pp. 4617-4631, 2019.
74. Y. Villuendas-Rey, J. A. Hernández-Castaño, O. Camacho-Nieto, C. Yáñez-Márquez, and I. López-Yañez. NACOD: A Naïve Associative Classifier for Online Data, IEEE Access, vol. 7, pp. 117761-117767, 2019.

75. Y. Villuendas-Rey, C. Yáñez-Márquez, J. A. Antón-Vargas, and I. López-Yáñez. An Extension of the Gamma Associative Classifier for Dealing With Hybrid Data, IEEE Access, vol. 7, pp. 64198-64205, 2019.

76. P. Moreno-Moreno, C. Yanez-Marquez, and O. A. Moreno-Franco. The new informatics technologies in education debate, International Journal of Technology Enhanced Learning, vol. 1, pp. 327-341, 2009.

77. C. Yanez-Marquez, I. Lopez-Yanez, O. Camacho-Nieto, and A. J. Arguelles-Cruz. BDD-based algorithm for the minimum spanning tree in wireless ad-hoc network routing, IEEE Latin America Transactions, vol. 11, pp. 600-601, 2013.

78. J. A. Hernández-Castaño, Y. Villuendas-Rey, O. Camacho-Nieto, and C. Yáñez-Márquez. Experimental platform for intelligent computing (EPIC), Computación y Sistemas, vol. 22, pp. 245-253, 2018.

79. C. Yu, X. Zhu, B. Feng, L. Cai, and L. An. Sentiment Analysis of Japanese Tourism Online Reviews, Journal of Data and Information Science, vol. 4, pp. 89-113, 2019.

80. R. Law, G. Li, D. K. C. Fong, and X. Han. Tourism demand forecasting: A deep learning approach, Annals of Tourism Research, vol. 75, pp. 410-423, 2019.

81. S. Sun, Y. Wei, K.-L. Tsui, and S. Wang. Forecasting tourist arrivals with machine learning and internet search index, Tourism Management, vol. 70, pp. 1-10, 2019.

82. F. Zhang, Q. Jiang, and Z. Wang. Forecasting Mode of Sports Tourism Demand Based on Support Vector Machine, in Proceedings of the 5th International Conference on Frontiers of Educational Technologies, 2019, pp. 154-158.

83. T. Qi, Y. Xu, and H. Ling. Tourism scene classification based on multi-stage transfer learning model, Neural computing and applications, vol. 31, pp. 4341-4352, 2019.

84. N. Saito, T. Ogawa, S. Asamizu, and M. Haseyama. Classification of tourism categories based on heterogeneous features considering existence of reliable results, in International Workshop on Advanced Image Technology (IWAIT) 2019, 2019, p. 1104905.

85. S. Giglio, F. Bertacchini, E. Bilotta, and P. Pantano. Using social media to identify tourism attractiveness in six Italian cities, Tourism Management, vol. 72, pp. 306-312, 2019.

86. K. Zhang, Y. Chen, and C. Li. Discovering the tourists' behaviors and perceptions in a tourism 
Claudia C. Tusell-Rey et al., International Journal of Emerging Trends in Engineering Research, 8(9), September 2020, 5939 - 5946

destination by analyzing photos' visual content with a computer deep learning model: The case of Beijing, Tourism Management, vol. 75, pp. 595-608, 2019.

87. E. Pantano and C. Dennis. Store buildings as tourist attractions: Mining retail meaning of store building pictures through a machine learning approach, Journal of Retailing and Consumer Services, vol. 51, pp. 304-310, 2019.

88. L. P. Lagunes, D. E. P. Rosado, J. C. Hernandez, L. G. Reynoso, and A. I. G. Sanchez. La cultura organizacional analizada a partir la teoría de los sistemas sociales autopoiéticos de Niklas Luhmann, Neumann Business Review, vol. 3, pp. 121-132, 2017.

89. A. V. Uriarte-Arcia, I. López-Yáñez, and C. Yáñez-Márquez. One-hot vector hybrid associative classifier for medical data classification.PloS one,Vol. 9, e95715, 2014)

90. V. C. Prakash, J. S. B. T. Reddy, J. R. Teja, A. B. V. Katesh, and M. V. Varma. An Expert System for Building a Cognitive and Career Prediction Model Based on N-Coin Puzzle Game.International Journal of Emerging Trends in Engineering Research,Vol. 7, pp. 410-416, 2019.

91. M. D. Lytras, H. Mathkour, H. L. Abdalla, C.Yáñez-Márquez, andP. O.De Pablos.The Social Media in Academia and EducationResearch R-evolutions and a Paradox: Advanced Next Generation Social Learning Innovation.J. UCS,Vol. 20, no.15, pp. 1987-1994, 2014.

92. W. N.Hussein, L. M.Kamarudin, M. R.Hamzah, H. N.Hussain, and K. J. Jadaa. A Methodology for Big Data Analytics and IoT-Oriented Transportation System for future implementation.International Journal of Emerging Trends in Engineering Research, Vol. 7, no. 11, pp. 449-453, 2019.

93. I. Salgado, C. Yañez, O. Camacho, and I. Chairez. Adaptive control of discrete-time nonlinear systems by recurrent neural networks in quasi-sliding mode like regime.International Journal of Adaptive Control and Signal Processing, Vol. 31, no. 1, pp. 83-96, 2017.

94. C. Lopez-Martin, C. Yanez-Marquez, and A. Gutierrez-Tornes. A fuzzy logic model based upon reused and new \& changed code for software development effort estimation at personal level. In Proc. IEEE2006 15th International Conference on Computing, 2006, pp. 298-303.

95. G. H. Sun, C. Y. Chen, H. Taud, C. Yáñez-Márquez, and S. H. Dong. Exact solutions of the 1D Schrödinger equation with the Mathieu potential.Physics Letters A, 126480, 2020.

96. J. E. Luján-García, C. Yáñez-Márquez, Y. Villuendas-Rey, and O. Camacho-Nieto. A Transfer Learning Method for Pneumonia Classification and Visualization.Applied Sciences, Vo. 10, no. 8, 2908, 2020.

97. N. Nawaz. Artificial Intelligence Face Recognition for Applicant Tracking System. International
Journal of Emerging Trends in Engineering Research, Vol. 7, no. 12, 2019. 